\title{
A novel one-sided push-out test for shear connectors in composite beams
}

\author{
M. A. Al-Shuwailia*, A. Palmeria ${ }^{\text {a }}$ M. Lombardo ${ }^{\text {a }}$

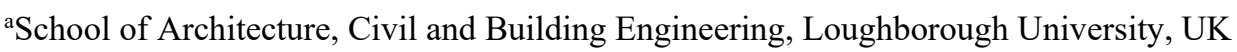 \\ *Corresponding author, e-mail address: m.a.al-shuwaili@lboro.ac.uk
}

\begin{abstract}
Push-out tests (POTs) have been widely exploited as an alternative to the more expensive full-scale bending tests to characterize the behaviour of shear connections in steel-concrete composite beams. In these tests, two concrete slabs are typically attached to a steel section with the connectors under investigation, which are then subjected to direct shear. The results allow quantifying the relationship between applied load and displacements at the steel-concrete interface. Since this relationship is highly influenced by the boundary conditions of POT samples, different experimental setups have been used, where the slabs are either restricted or free to slide horizontally, as researchers have tried to reduce any discrepancy between POT and full-scale composite beam testing.

Based on a critical review of various POT configurations presented in the dedicated literature, this paper presents an efficient one-sided POT (OSPOT) method. While OSPOT and POT specimens are similar, in the proposed OPSPOT setup only one of the two slabs is directly loaded in each test, and the slab is free to move vertically. Thus, two results can be obtained from one specimen, i.e. one from each slab. A series of POTs and OSPOTs have been conducted to investigate the behaviour and the shear resistance of headed stud connectors through the two methods of testing. The results of this study than were compared with those of different POTs setups conducted by other researchers. The new OSPOT results show in general an excellent agreement with the analytical predictions offered by both British and European standards, as well as the estimated shear resistance proposed other researchers in the literature.

These findings suggest that the proposed one-sided setup could be used as an efficient and economical option for conducting the POT, as it has the potential not only to double the number of results, but also to simplify the fabrication of the samples, which is important in any large experimental campaign, and to allow testing with limited capacity of the actuator.
\end{abstract}

Keywords: composite beams; push-out test; shear resistance; headed studs.

\section{Introduction}

Shear connectors joining the concrete slab to the steel section define the characteristic behaviour of the composite beams. As such, the relationship between applied load $(P)$ and relative displacement, i.e. slip, at the steelconcrete interface $(\delta)$, the so-called $P$ - $\delta$ curve, is of key importance in the design of these beams, as it shows the ductility, stiffness $(\mathrm{K})$ and the resistance of the connectors (see Fig. 1(a)).
Ideally, the $P-\delta$ curve should be directly obtained from full-scale beam testing. However, the complexity of the shear transfer mechanism between concrete and steel, due to the indirect loading of the connectors by the flexural forces within the composite beam, along with the variety of devices and methods of connection, makes it unattainable to determine the characteristic behaviour of shear connectors from full-scale composite beam tests. Further, as noted by Oehlers \& Bradford [1]"composite beam tests are expensive and 
this would prohibit the development of shear connectors".

As a consequence, the small-scale pushout test (POT) method (see Fig. 1(b)) has been extensively adopted as a valuable alternative to the full-scale beam testing, not only due to the size of the POT specimen and its economy, but also for the following reasons: i) investigating under the direct shear loading offers a clear view about the performance of shear connector; ii) a wide range of parameters can be investigated and the characteristic behaviour of shear connectors can be evidenced; iii) the behaviour of different types and sizes of shear connectors can be compared [2].

As shown in Fig.1(b), in the traditional POT, two identical reinforced concrete blocks (slabs) are bonded to a steel section, usually I shaped, by means of the shear connectors under investigation. After the designed aging time, a hydraulic jack is used to apply a direct longitudinal shear force to the steel section of the specimen. The relative longitudinal movement, at the concrete-steel interface, in the load direction is measured and plotted against the applied load to present the P- $\delta$ curve.

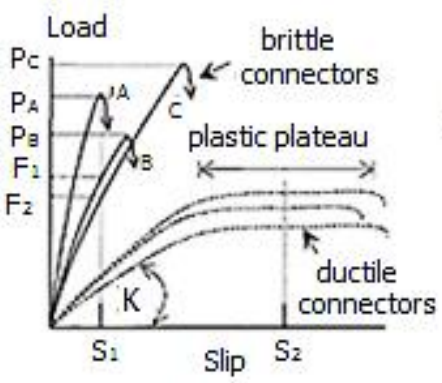

(a)

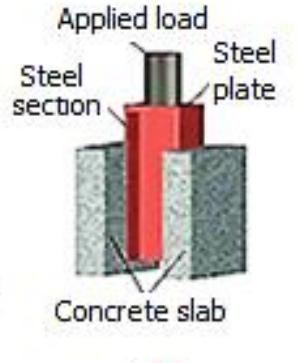

(b)
Fig. 1. (a) P- $\delta$ curve [1], (b) POT specimen

Nevertheless, different specimen sizes, with one or two concrete slabs, and setups have been used in the attempt of reducing any discrepancy with the results of full-scale beam testing. In these various setups, the base of the specimen is either restricted or free to slide in the horizontal direction.

In this paper, some of the deficiencies in the traditional POT, especially the frictional force at the base, are addressed, and a new OSPOT setup is presented. While in the conventional POT the two slabs are tested simultaneously by applying the load to the steel profile, which is free to move in the load direction, in the proposed OSPOT setup only one of the two slabs is directly loaded in each test, in which the slab is free to move vertically. In this way the frictional forces at the base of the slabs are eliminated and two results can be obtained from one specimen, i.e. one from each slab. Also, contrary to other OSPOT configurations, the new setup allows more versatility and a wider range of specimens to be teste

\section{Push-out test (POT) configurations}

The results obtained from a POT are highly influenced by the boundary conditions of the concrete slab, especially the frictional reactions at the base (see e.g. [3],[1] and [4]). Also, the variation in the size of the POT specimens and the setups cause the scatter in the POT results. This variation is even among the code of practices: for instance, the Eurocode POT specimen size is (300x650x 150) and the base usually embedded in mortar or gypsum Eurocode-4 (EC-4)[5] while the British Standards (BS-5)[6] recommends $(300 \times 460 x 150)$ specimen size and the base to be supported by a hard base.

\subsection{Discuss the POTs' results}

Oehlers \& Johnson [3] believe that the conventional setup of the POT increases the connectors shear resistance because of the induced frictional forces under the slabs of the specimen. They assessed more than 100 POTs, with nearly half of the data taken from the work conducted by Ollgaard et al. [7]. The authors concluded in Ref. [3] that in the typical POT, where the slabs are not restraint nor free to move, a horizontal frictional force $(H)$ acts

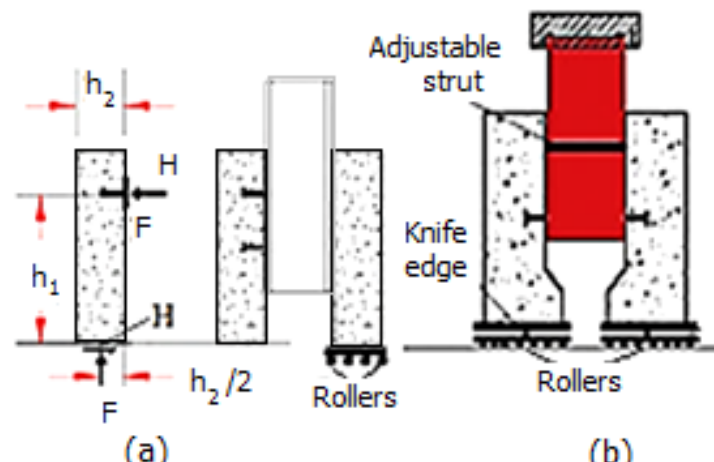

(a)

Fig. 2. (a) Frictional force analysis [1] and (b) knifeedged setup [3] 
under the concrete slabs, as shown in Fig. 2 (a), affect the POT results.

To quantify the effect of the friction force $H$, several POTs were conducted, in which the slabs were supported by knife-edged bases consequently the frictional force was negligible (see Fig. 2(b)).

The authors [3] concluded that Ollgaard et al. [7] POT results were exaggerated by about $19 \%$ due to presence of the friction force $\mathrm{H}$ [1].

To reduce or eliminate this effect, Oehlers $\&$ Bradford [1] suggested a horizontal slice to support one of the two slabs of the POT specimen while the other one is fixed. However, as shown in Fig. 3, Loh et al.[8] tested three POT samples according to this setup, and one of them failed early due to the disproportionate movement toward the outside of the roller support, and the results of the other two were about $20 \%$ higher than the expected resistance of the shear connectors.

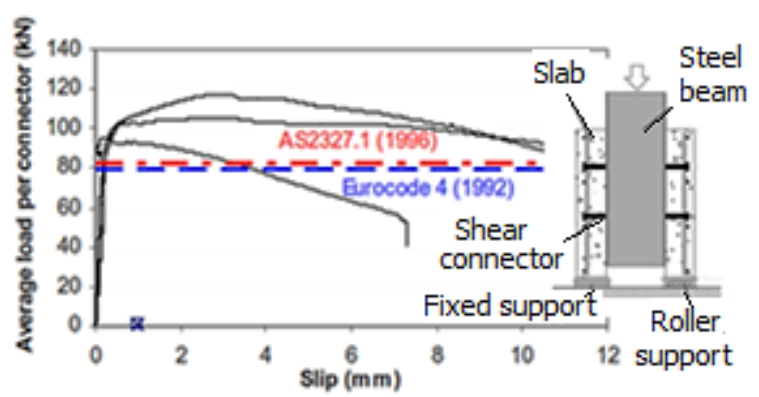

Fig. 3. POT setup and results by [6]

Other researchers suggested a horizontal restraint to counterbalance or reduce the frictional effect (see Fig. 4) [9] . However, according to Rambo-Roddenberry[10] applying a direct horizontal force to the concrete blocks may increase the frictional resistance at the steel-concrete interface, and thus overestimate the strength of the headed studs. For instance, applying $10 \%$ of the applied force as a horizontal restraint leads to a $14 \%$ increase in the shear resistance.
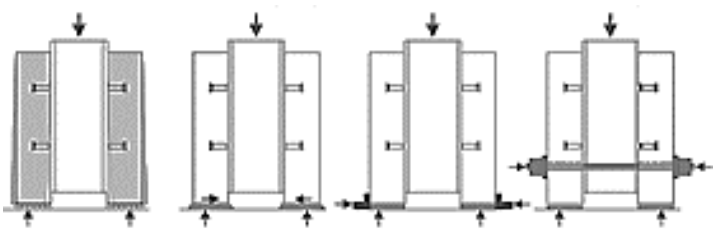

Fig. 4. Various POT setups reviewed by [7].

\subsection{One-sided push-out test (OSPOT)}

OSPOT is also an attempt to reduce the discrepancy in the results of the POTs testing and the full-scale beam tests. It has been used by many researchers and did not show any significant effect on the behaviour of the shear connectors [11].

The one-sided push-out test (OSPOT) method avoids the unnecessary duplication of concrete blocks in the POT as the weaker connector usually failed first and thus the result of the POT is the average of the two connectors of the specimen. Avoiding the duplication means a signification reduction in labour, cost and time.

Hicks \& McConnel [4] modified the standard POT to achieve a vertical OSPOT, aiming to simplify the testing process and to eliminate the frictional effects at the base of the concrete slabs. In their setup, the slab was supported at the base by two-directional rollers; however, this setup did not simulate the loading conditions in full-scale testing and use of the roller bearings caused a significant reduction in the shear connector strenght [11].

Lam[2] presented a horizontal OSPOT (see Fig. 5), in which a $(600 \times 800 \times 150) \mathrm{mm}$ concrete slab is bonded to the steel section by a row of 6-19 mm shear studs. A jack attached to the steel section applies the load horizontally to the slab, which is free to move in the load direction, i.e. free of frictional resistance at the base. The author indicated that the results agreed well with the resistance strength specified in the design BS-5 [6], EC-4 [5], as well as the equation to predict the studs shear strength offered by Oehlers \& Johnson [3].

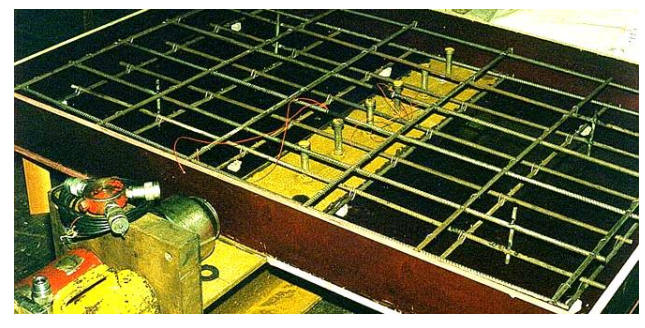

Fig. 5. Test setup by [2].

However, this setup requires a special testing rig to accommodate the large concrete slab of testing. Also, the connector shear resistance is obtained from the division of the failure load by the number of the connector 
despite the indication that the first stud usually fails before the other stud during the testing.

Ernst [11] employed the vertical OSPOT test setup shown in Fig. 6(a). The load is applied through a horizontal spreader beam attached to the single slab. At the top, a mounted lateral restraint (a roller) supports horizontally the spreader beam during the test. The slab is bonded to a vertical steel tube section via the shear connectors under investigation. The tube is joined to a base plate to resist the reactionary forces during the test.

The author, however, reported that the results of some tests were potentially affected by some inconsistent. Indeed, the eccentric high loading, which is required for specimens with a large number of studs, induces a separation between the spreader loading beam and the specimens during the test. This separation increases the horizontal movement in the top part of the specimen which behaves similarly to a cantilever column (see Fig. 6(b)).

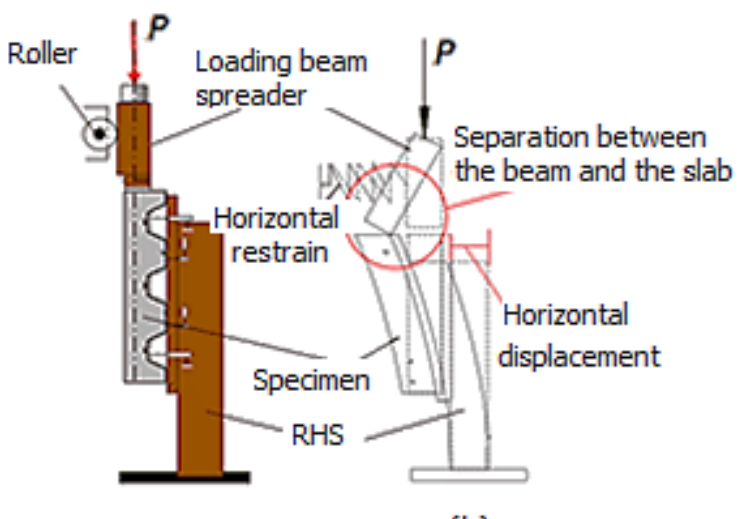

(a)

(b)

Fig. 6. (a)Setup by [9] and (b) the horizontal movement during the test

\section{The new setup concepts}

Beside eliminating the frictional reaction at the base of the concrete slab (see Fig. 2(a)), Fig. $7(a, b)$ shows the concepts which have been adopted in this study to modify Ernst's [11] testing method shown in Fig. 6(a) and devise more reliable OSPOT:

- Removing the load spreader beam. In the new setup, the load is applied directly to the concrete slab via a thick plate. By eliminating the separation between the loading plate and the slab, the horizontal movement at the top is prohibited.

- Adding a vertical restraint at the top of the steel section. A bracing of $10 \times 10 \mathrm{~mm}$ steelbox beam, which crosses in parallel to the slabs, provides more stability to the specimen and prevents it from leaning forward during the test, as the line of action of the applied shear load to the concrete slab is eccentric to the reaction at the base of the steel beam.

- Adding a secondary horizontal restraint at the base of the steel section. For practical reasons, the specimen's I steel section is not welded to the floor base plate; instead two $10 \times 10 \mathrm{~mm}$ box beams are positioned vertically and parallel to the slab direction, to prevent the sliding of the sample during the test.

- Fabricating two-slabs specimens. This provides more stability to the sample during the casting and preparations before and after the first test.

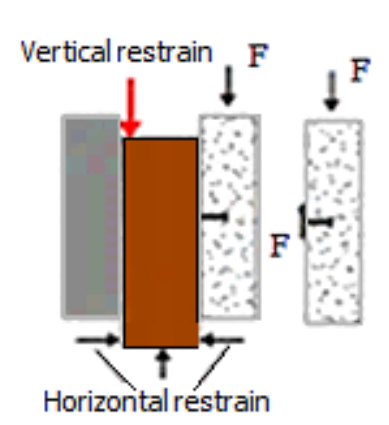

(a)

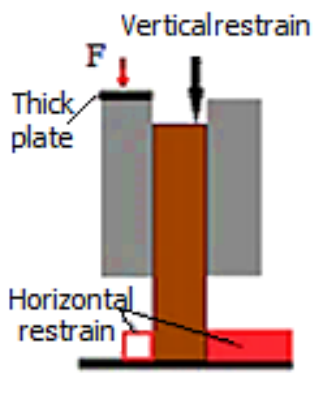

(b)
Fig. 8. (a) Eliminating the frictional reaction, (b) concepts of the new OSPOT setup.

\subsection{OSPOT setup}

The concepts mentioned in section 3 are applied in the new OSPOT setup (see Fig. 8).

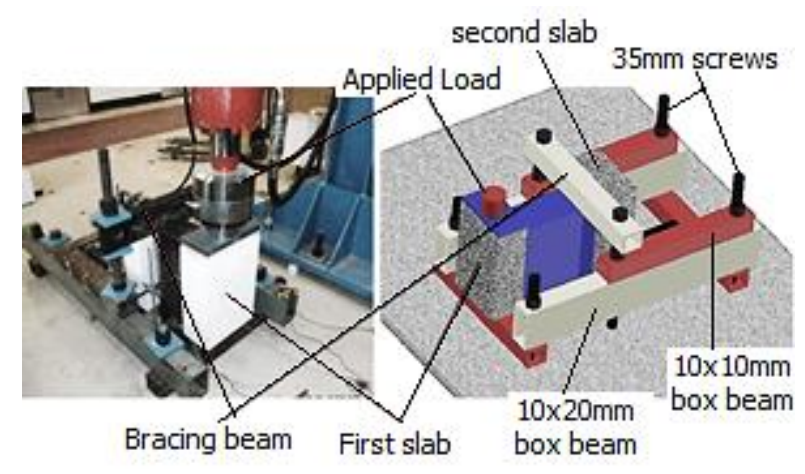

Fig. 7. The new OSPOT setup. 
A supporting frame is assembled from (10x10 and 10x20) mm steel-box sections, which are jointed and connected to the floor by means of $35 \mathrm{~mm}$ steel screws. The 10x10 mm bracing beam, is fastened to the top part of the specimen steel section by two long $35 \mathrm{~mm}$ screws. The secondary horizontal restraint is secured to the base of the steel section, to halt the sliding during the test, by two steel boxes tightened to the floor and the supporting frame also.

\section{Experimental program}

\subsection{Specimens detailing}

A total of nine tests were fabricated identically with the same geometrical configurations. Each specimen employs two 19 x $80 \mathrm{~mm}$ shear studs (one on each side except the last POT which had two studs on each side) welded directly to a $560 \mathrm{~mm}$ long universal beam, 254x146x43 UB, and bonding two 460x 300x150 (height $\mathrm{x}$ width $\mathrm{x}$ thickness) $\mathrm{mm}$ concrete slab to the greased flanges of the steel section. The tensile stress of the shear studs $\left(f_{u c}\right)$ was $523 \mathrm{~N} / \mathrm{mm}^{2}$.

Three of these specimens were tested by the typical POT, consistently with the BS-5[6], to provide a comparison data to the OSPOT and others. The rest specimens were tested according to the new OSPOT setup shown in Fig. 8. In the OSPOT specimens, an extra steel plates of $12 \mathrm{~mm}$ thickness was welded to the bottom of the steel section to provide a uniform load distribution to the resulting reaction at the base of the UB beam.

These set designated as OSPOT-ds-C (ds is the diameter of the stirrups and $\mathrm{C}$ is the compressive strength). For example, OSPOTds10-29 means one-sided POT, the stirrups diameter is $10 \mathrm{~mm}$, and the compressive strength is $29 \mathrm{~N} / \mathrm{mm}^{2}$. The typical POTs designated as POT-ds-C at the same concepts.

\subsection{Tests loading procedure}

A hydraulic jack with a nominal design capacity of $600 \mathrm{kN}$, was used for the all tests. Two steps of monotonic loading were adopted: (i) a load controlled $(1 \mathrm{kN} / \mathrm{sec})$ up to $40-50 \%$ of the estimated failure load, for 3-5 cycles of loading.

(ii) displacement controlled loading of $(0.03 \mathrm{~mm} / \mathrm{sec})$ starting from zero until failure.
Subsequent loads testing was imposed in such a way that failure occurs after more than 15 minutes of the test starting, so to comply with the BS-5[6] and EC-4[5] recommendations.

\subsection{OSPOT testing}

Initially, four identical OSPOT-ds10 samples were fabricated as shown in Fig. 9. Each slab was reinforced by 4-Ø10 longitudinal bars enclosed by $2-\varnothing 10$ stirrups and the clear distance between the stirrups was $250 \mathrm{~mm}$.

This study specimens were a copy of work conducted by Xue et al [12], who tested $19 \times 103 \mathrm{~mm}$ shear studs embedded in a $460 \times 300 \times 120$ concrete slab (one stud on each side) but by POT and according to EC- 4 where the base in either embedded in a mortar or a gypsum. The authors conducted two set (6 POT samples) as shown in Table 1.

In the first group of this study, four OSPOTs were tested in two different compressive strength $(29 \& 34) \mathrm{N} / \mathrm{mm}^{2}$ aiming: to examine the consistency between the identical twin samples; to compare the results

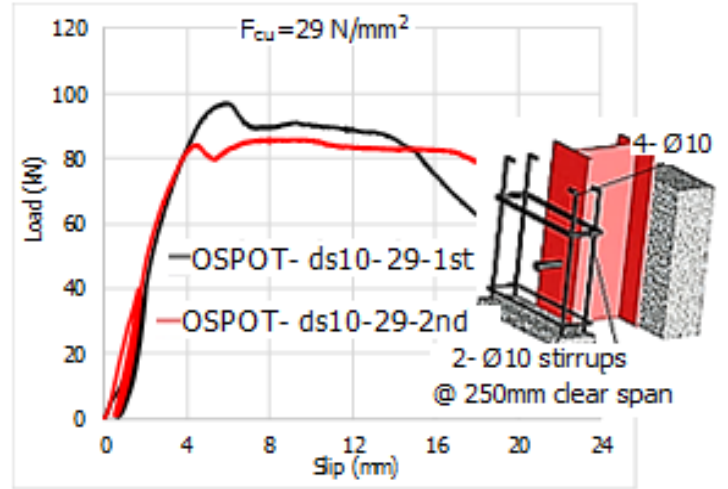

Fig. 9. P- $\delta$ for OSPOT-ds10-29 set.

of OSPOTs with the BS-5[6], EC-4[5] and Oehlers \& Johnson [3] shear resistance estimations, also to compare with the POTs in this research and other the tests conducted by authors; to investigate the effect of different c oncrete compressive strength on behaviour of the shear studs in this method of testing.

The results of the two OSPOTs $\left(\mathrm{F}_{\mathrm{cu}}=29\right)$ were consistent and the difference in shear resistance between the first set is less than $4 \mathrm{kN}$ and the average was $84 \mathrm{kN}$ per stud (see Fig. 9).

In the second set, an error during the concrete casting led to a partial encasement to one of the flanges which is under the direct loading, this encasement has increased the 
shear resistance as the vertical slab movement during the test was interrupted by this encased part (see Fig. 10).

The difference between the identical twin samples was about $18 \mathrm{kN}$ which is still within the requirements of EC-4 [5]Clause B.2.5 for evaluation POT results that considered the

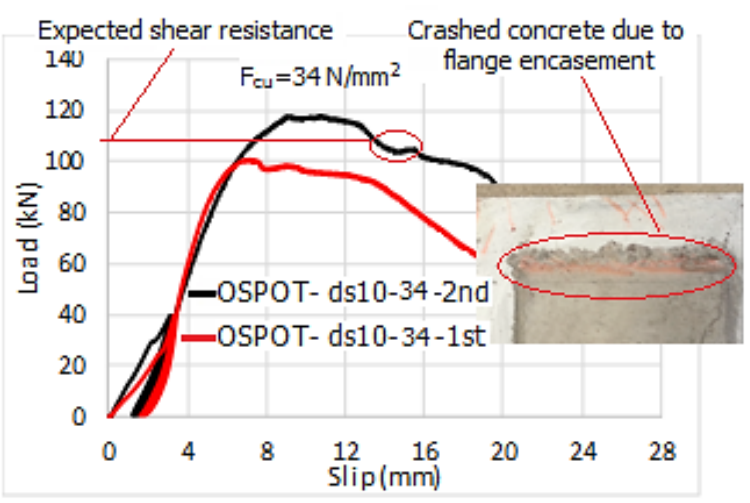

Fig. 11. P- $\delta$ for OSPOT-ds10-34 set.

scatter in these results. This recommendation accepts the individual result which diverts by less than $10 \%$ of the average of the identical set of specimens. The expected resistance is about of this side was $102 \mathrm{kN}$ which make the average for this set is $101 \mathrm{kN}$ (see Fig. 10).

The third twin of OSPOT specimen, is not identical. The tests OSPOT-ds10-18 \& OSPOT-ds8-18 were designed to investigate two parameters: firstly, the compressive strength of the concrete and secondly, to study the effect of the redistribution of the transverse steel (stirrups) on the shear resistance at the same compressive strength. The area of steel for two rebars of diameter $10 \mathrm{~mm}$ is equal to $157 \mathrm{~mm}^{2}$ which is nearly the same steel area of three rebars of $8 \mathrm{~mm}$ in diameter.

Hence, the steel layout was 2$\varnothing 10$ \& 3- Ø 8 stirrups plus 4-10 longitudinal bars for the same specimen. The shear resistances were convergent, OSPOT-ds8-18 resistance was higher by $6 \mathrm{kN}$ and shown more elastic behaviour (see Fig. 11).

\subsection{POT testing}

Two of the three POTs samples, i.e. POTds8-19.4 \&POT-ds10-16.8, were designed to compare with the third OSPOT-18 the results. Therefore, both of the POT sample were casted nearly at the same concrete compressive strength (about $3 \mathrm{~N} / \mathrm{mm}^{2}$ difference) and the same steel layout for each specimen (i.e. 3-Ø8 \&2-Ø10 stirrups and 4-Ø10 longitudinal bars). In these two tests, a $30 \mathrm{~mm}$ thick steel plate was placed under the POT specimens to comply with the BS $-5[6]$ requirement.

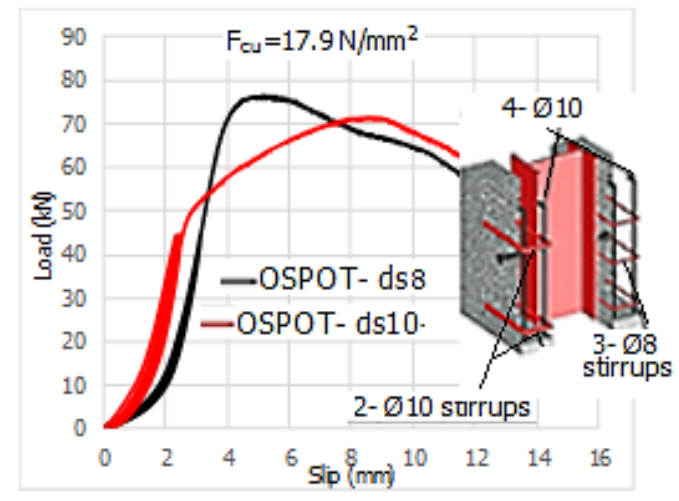

Fig. 10. P- $\delta$ for OSPOT-17.9.

Despite the sudden drop (see Fig. 12) in the loading of POT-ds8 due to partial encasement at the steel section from one side, the results were in good agreement between the two samples, however, the shear resistance was more than the expected results.

The average shear resistance was $105 \mathrm{kN}$ per stud. The results of these two tests might

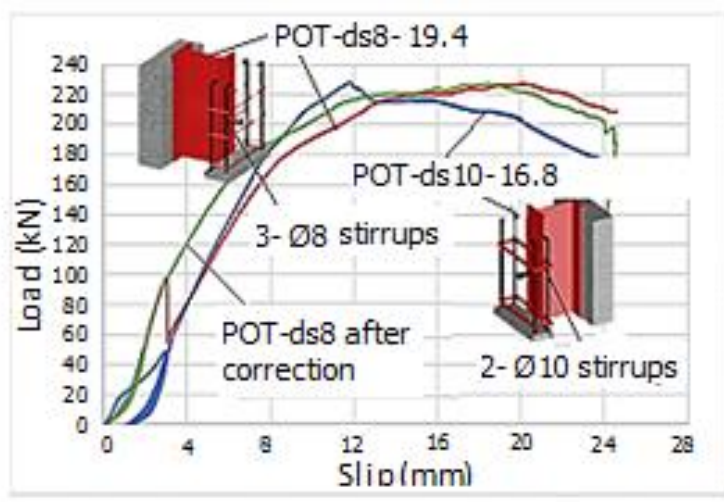

Fig. 12. P- $\delta$ for POT-ds8 \& POT-ds10.

confirm Oehlers \& Johnson [3] observation about the effect of the frictional force $(\mathrm{H})$. In fact, applying their suggested reduction factor of $19 \%$, makes shear resistance equal to $85 \mathrm{kN}$, which leads to more consistence results with both the OSPOT, Xue et al. [12] results and the codes of practices BS-5 and EC-4.

As it was mentioned in section 1.1, in the POT tests carried by Loh et al. [8] (see Fig. 12), the concrete compressive strength and the 
failure load were $20.5 \mathrm{~N} / \mathrm{mm}^{2}$ and about 110 $\mathrm{kN} /$ stud respectively. These results are nearly the same result of the POTs in this research without correction, i.e. POT- ds8 and POTD10, which might indicate that the sliding rollers failed to eliminate or reduce significantly the frictional force effect.

The $9^{\text {th }}$ test, POT-ds12-48, employed 2 headed studs at each side, i.e. 4 studs in total, and was designed to investigate more the effect of the rebars and compare the results the previous tests and. However, in the last test up to $515 \mathrm{kN}$ the sample did not fail, the actuator failed the reach the designed maximum load. From the previous results the expected failure load is $500 \mathrm{kN}$, adding the exaggeration of $19 \%$ due to the base condition, this makes the expected failure load about $600 \mathrm{kN}$.

\section{Failure mode and tests results}

\subsection{Failure mode}

In all the OSPOT specimens, the failure mode occurred due to the shank shearing just above the weld collars, where the headed studs are partially fractured, which aligned with the finding of Oehlers \& Bradford [1] about the studs' failure (see Fig. 13(a,b)).

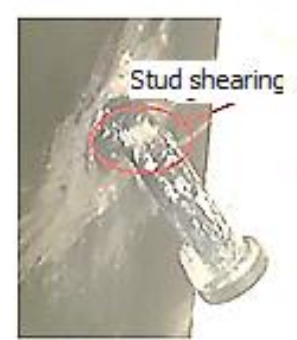

(a)

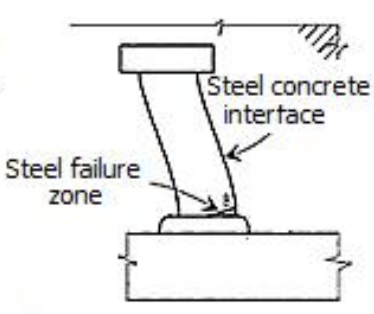

(b)
Fig. 13. (a) Stud failure (b) failure mechanism [1].

A local crushing of the concrete in front of the shear stud was observed on the back side of the slab. Usually, four radial cracks converging at the vicinity of the stud were clearly visible. Post failure, the headed studs remained embedded in the concrete of the slabs despite the complete separation between the slab and the steel section.

\subsection{Ductility discussion}

Loh et al. [13] tested three full-scale (3meter in length) composite beams. They observed that the failure mode was the fracture of the connectors above the weld collar and averaged shear resistance was $101 \mathrm{kN} / \mathrm{stud}$. In these tests, the concrete compressive strength was $31.5 \mathrm{~N} / \mathrm{mm}^{2}$ and stud tensile stress is 466 $\mathrm{N} / \mathrm{mm}^{2}$. The average slip at the failure was 16 $\mathrm{mm}$ which is in good consistence with OSPOT results for nearly the same parameters and dose not agreed with the authors POTs in which a brittle failure is observed.

Generally, the load-slip curves from POT show some brittleness compare to the curves from the full-scale composite beams and the reason is the deficiency in the POT specimen rather than the shear connection [14]. Indeed, the comparison between Xue et al.[12] POT results and the resulting load-slip curves of OSPOT which show noticeably a higher degree of ductility.

\section{$5.3 \quad$ Evaluation of tests results}

A summary of the test results is presented in Table 1 . The results show that, in general, the OSPOT of this study and work conducted by Lam [2] are in good consistent with the three predictions of BS-5[6], EC-4[5] and Oehlers \& Johnson [3] compared to the POTs carried by Xue et al. [12].

Indeed, the evaluation of the OSPOTs results together, i.e. vertical of this study and horizontal of [2], indicates that the OSPOT setup in this research is in better consistent with the shear resistance estimations offered by BS-5, EC-4, and Oehlers\& Johnson [3].

Table 1. A comparison between results of this research and [2] and [12].

\begin{tabular}{|c|c|c|c|c|c|c|}
\hline Autor(s) & Test ref. & $F_{c t}$ & $q(k N)$ & a/ ref.:[6] & a/ret.[S] & a/ret. [3] \\
\hline \multirow{5}{*}{ 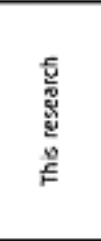 } & $\begin{array}{l}\text { OSPOT-dS } \\
\text { OSPOT-dS10 }\end{array}$ & 17.9 & 70 & 0.91 & 1.13 & 1.00 \\
\hline & $\begin{array}{l}\text { OSPOT-ds10 } \\
\text { OSPOT- } d s 10\end{array}$ & 29 & 84 & 0.95 & 0.97 & 0.94 \\
\hline & $\begin{array}{l}\text { OSPOT-ds10 } \\
\text { OSPOT-ds10 }\end{array}$ & 34 & 100 & 1.05 & 1.03 & 1.03 \\
\hline & $\begin{array}{l}\text { POT-ds8 } \\
\text { POT- } 4610\end{array}$ & 18.1 & $85^{*}$ & 0.91 & 1.37 & 1.21 \\
\hline & POT-ds12 & 48 & \multicolumn{4}{|c|}{ Specimen did not foil } \\
\hline \multirow{5}{*}{ 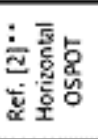 } & $\mathrm{RC1}$ & 15.3 & 71.7 & 0.75 & 1.19 & 0.90 \\
\hline & $8 C 2$ & 29.1 & 102.6 & 1.03 & 1.15 & 0.91 \\
\hline & $\mathrm{RC} 3$ & 28.5 & 101.6 & 1.02 & 1.16 & 0.91 \\
\hline & $R C 4$ & 28 & 100.1 & 1.00 & 1.15 & 0.91 \\
\hline & RC5 & 51.1 & 133.2 & 1.22 & 1.17 & 0.87 \\
\hline \multirow{3}{*}{$: \underset{z}{\check{z}}$} & STUD16-17 & 38 & 100.5 & 0.97 & 1.32 & 1.31 \\
\hline & STUD 18 & 38 & 104 & 1.00 & 1.36 & 1.36 \\
\hline & STUD13-15 & 50.7 & 111 & 0.93 & 1.38 & 1.25 \\
\hline \multicolumn{7}{|c|}{ the results was reduced by $19 \%$ according to Cehlers } \\
\hline \multicolumn{7}{|c|}{ * The results were adopted directly from the atthorc } \\
\hline \multicolumn{2}{|c|}{ Eurocote [S] } & \multicolumn{5}{|c|}{$q_{s !}=\min \left(0.29 d^{2} \sqrt{f_{f}^{\prime} E_{c}}, 0.8 f_{L !} A_{d e}\right)$} \\
\hline \multicolumn{2}{|c|}{ Oehlers \& Johnson [3] } & \multicolumn{2}{|c|}{$q_{z:}=4\left[\frac{f_{t:}}{f_{t t}}\right.$} & ]$^{\text {css }}\left[\frac{E_{\varepsilon}}{E_{t:}}\right]^{0}$ & \multicolumn{2}{|c|}{$A_{b c} i_{i x}$} \\
\hline
\end{tabular}


The reason could be in the horizontal OSPOT, several headed studs were tested together in one specimen which may lead to a re-distribution to the shear stress among the studs before the failure state especially after the failure of the weak stud(s), normally the first stud, as the resistance is the average and not individual result.

\section{Conclusions}

In this study, six one-sided push-out tests (OSPOTs) and three POTs have been carried out, and the results obtained from these tests compared against each other. The results of this study have also been compared with the horizontal OSPOTs performed by Lam [2] and the POTs executed by Xue et al. [12]. All the 20 tests in these three studies then have been evaluated against the studs' shear resistance estimation offered by codes of practices BS- 5 [6] and EC-4 [5] as well as the equations for shear resistance presented by Oehlers \& Johnson [3]. From these investigations, the following conclusions can be drawn:

- Due to the test setup, the POT results performed on a solid base tend to provide a higher shear resistance, about $20 \%$ more than the OSPOT.

- The vertical OSPOT results obtained as a part of this study are in good agreement with horizontal setup results, and the results of the new vertical setup are consistently in good agreement with the horizontal OSPOT and the predictions reported in the Refs. [11], [12] and [3].

- The load-slip curves obtained from the proposed OSPOT show a higher degree of ductility, which might be representative of the real load-slip relationship in full-scale composite beams, where the studs typically show a ductile behaviour.

- The re-distribution of the area of the transverse steel (stirrups) has increased both the shear resistance, about $7 \%$, and the elastic range behaviour of the shear studs, about $45 \%$. The proposed testing method has a significant potential to reduce time and cost of experimental campaigns on shear connectors.

\section{Acknowledgements}

The first author acknowledges thankfully the financial support of the Iraqi government and the
University of Kufa, in his Ph.D. studies at Loughborough University.

\section{Reference}

[1] Oehlers DJ, Bradford MA. Composite Steel and Concrete Structures: Fundamental Behaviour. Elsevier; 1995.

[2] Lam D. Capacities of headed stud shear connectors in composite steel beams with precast hollowcore slabs 2007;63:1160-74.

[3] Oehlers, DJ, Johnson, RP. The strength of stud shear connections in composite beams. Struct Eng 1987;56:44-8.

[4] Hicks, SJ, McConnel, RE. The shear resistance of headed studs used with profiled steel sheeting. ASCE 1997:325-38.

[5] European Commitee for Standardization. Eurocode 4: Design of composite steel and concrete structures - Part 2: General rules and rules for bridges. vol. 2. 2005.

[6] BS5400-Part 5: Code of practice for the design of composite bridge, London: British Standards Institution.2005.

[7] Ollgaard JG, Slutter RG, Fisher JW. Shear strength of stud connectors in lightweight and normal weight concrete. AISC 1971;13:5564.

[8] Loh HY, Uy B, Bradford M. Behaviour of Partial Strength Composite Steel-Concrete Joints Incorporating Various Novel Features. Proc. 7th Pacific Struct. Steel Conf. held Long Beach, CA,2004, n.d.

[9] Döinghaus P. Zum Zusammenwirken hochfester Baustoffe in Verbundträgern 2001.

[10] Rambo-Roddenberry M. Behavior and strength of welded stud shear connectors (Doctoral dissertation, Virginia Tech) 2002.

[11] Ernst S. Factors Affecting the Behaviour of the Shear Connection of Steel-Concrete Composite Beams 2006.

[12] Xue W, Ding M, Wang H, Luo Z. Static Behavior and Theoretical Model of Stud Shear Connectors. J Bridg Eng 2008, 13(6), 623-634.

[13] Loh HY, Uy B, Bradford MA. The effects of partial shear connection in the hogging moment regions of composite beams Part I Experimental study. J Constr Steel Res 2004;60:897-919.

[14] Hicks SJ, Smith AL. Stud shear connectors in composite beams that support slabs with profiled steel sheeting. Struct Eng Int J Int Assoc Bridg Struct Eng 2014;24:246-53. 